\title{
Genetic Structure of the Phytophthora infestans Population in Morocco
}

\author{
M. Sedegui, Former Graduate Fellow, R. B. Carroll, Professor, A. L. Morehart, Professor, and T. A. Evans, \\ Associate Professor, Department of Plant and Soil Sciences, University of Delaware, Newark 19717-1303; S. H. \\ Kim, Plant Pathologist Supervisor, Plant Disease Diagnostic Laboratory, Pennsylvania Department of Agriculture, \\ Harrisburg 17110; and R. Lakhdar, Director, and A. Arifi, General Director, Ministry of Agriculture, Rabat, \\ Morocco
}

\begin{abstract}
ABSRACT
Sedegui, M., Carroll, R. B., Morehart, A. L., Evans, T. A., Kim S. H., Lakhdar, R., and Arifi, A. 2000. Genetic structure of the Phytophthora infestans population in Morocco. Plant Dis. 84:173176.

In 1996 to 1998, a late-blight survey was conducted in potato- and tomato-growing regions of Morocco. A total of 149 isolates of Phytophthora infestans were collected and analyzed for the glucose-6-phosphate isomerase ( $\mathrm{Gpi}$ ) and peptidase (Pep) alleles, mating types, and metalaxyl sensitivities. Four genotypes were identified: MO-1 (mating type A1, Gpi 100/100, Pep 92/100), MO-2 (mating type A1, Gpi 86/100, Pep 92/100), MO-3 (mating type A2 Gpi 100/100, Pep 100/100), and MO-4 (mating type A1, Gpi 100/100, Pep 100/100). The potato isolates were MO-1 (1996 \& 97), MO-3 (1998), and MO-4 (1998). The frequencies of A1 (MO-4) and A2 (MO-3) mating types in potato fields in 1998 were 26 and 74\%, respectively. Potato isolates were pathogenic to both potatoes and tomatoes. The isolates collected from tomatoes in 1997 and 1998 were MO-2. Potato and tomato isolates were insensitive and sensitive to metalaxyl, respectively. The change of genotype population in 1998 was probably caused by migration of a new genotype from Europe associated with importation of potato seed. The detection of A1 and A2 mating types in the same potato field indicates the potential for sexual reproduction of $P$. infestans in Morocco.
\end{abstract}

After 150 years, late blight caused by Phytophthora infestans (Mont.) de Bary still emerges as a major disease on potato and tomato (17). The pathogen arrived in Europe in 1840 and was spread by wind at about $500 \mathrm{~km}$ per year to virgin territory. In 1941, $P$. infestans was introduced to Africa on imported potato seed from the United Kingdom in order to feed Allied troops during World War II (3).

Recently, A1 and A2 mating types of $P$. infestans have been found in most parts of the world, and genetic markers have permitted workers to map the global migrations of this pathogen (10,12-14). Analysis of a limited global collection of isolates demonstrated that a single clonal lineage, US-1 genotype, is present in most countries where potatoes are grown $(14,16-$ $18,24)$. This lineage is defined by a particular restriction fragment length polymorphism (RFLP) banding pattern with the probe RG 57, the glucose-6-phosphate isomerase (Gpi) 86/100, the peptidase (Pep) $92 / 100$, and the mating type A1 $(1,9,15,17)$.

Corresponding author: R. B. Carroll

E-mail: rbc@udel.edu

Accepted for publication 23 October 1999.

Publication no. D-1999-1213-02R

(C) 2000 The American Phytopathological Society
In Mexico, the center of origin of $P$. infestans, the fungus reproduces sexually and the concept of clonal lineage has very limited value. Sexual reproduction is now thought to occur in several parts of Europe (7,25).

In Morocco, potato (Solanum tuberosum) and tomato (Lycopersicum esculentum) are important crops, and represent $80 \%$ of the vegetable production acreage. In addition to their importance for local consumption, they are the major vegetables grown for export (average: 350,000 tons/year) and are second only to citrus. Recently, late blight has emerged as the most important disease on potato and on field-grown and plastic-house tomatoes. All of these crops are grown year-round. The pathogen $P$. infestans may survive in potato seed or on potato and tomato plants from one crop to another. The fungus is omnipresent in potato and tomato fields and is favored by the climatic conditions (high humidity and moderate temperatures) of the production area, which makes late blight difficult to manage. Isolates of $P$. infestans in Morocco have not been characterized or the genetic structure of this fungus population determined.

The purpose of this study was to characterize the genetic diversity of the $P$. infestans populations in Morocco.

\section{MATERIALS AND METHODS}

Collection of samples. A survey was conducted for the presence of late blight in vegetable-growing regions of Morocco between 1996 and 1998. Isolates of P. infestans were collected from fields of potatoes and tomatoes that showed late-blight symptoms. The pathogen also was isolated from infected tubers imported into Morocco from Europe. Growers were contacted to obtain information on recent fungicide applications, cultural practices, and storage techniques used for their potato crop. Volunteer plants left in the field and solanaceous weeds such as Solanum sarrachoides (26) that could affect the survival of the fungus in the field were also sampled.

Isolates from Morocco were imported into Delaware under quarantine guidelines and a permit from APHIS (Animal and Plant Health Inspection Service). All in vitro studies were conducted in accordance with bio-safety regulations.

Isolation and maintenance of isolates. Isolates were obtained from commercial potato and tomato and imported seed potatoes. Some isolates were obtained from potato fields that had received several applications of the fungicide metalaxyl. All isolates were taken from single lesions on infected potato and tomato leaves, stems, tubers, and fruits. Infected tissues were surface disinfected in $0.5 \% \mathrm{NaOCl}$ for 2 to $3 \mathrm{~min}$, then placed on selective media, either pea agar amended with different antibiotics (19) or PARP (1 liter of deionized water containing $17 \mathrm{~g}$ of cornmeal agar amended with the following antibiotics: 10 $\mathrm{mg}$ of pimaricin, $250 \mathrm{mg}$ of ampicillin, 10 $\mathrm{mg}$ of rifampicin, and $100 \mathrm{mg}$ of pentachloronitrobenzene; 2 ), then incubated at 18 to $20^{\circ} \mathrm{C}$ in darkness for 7 to 10 days. Each isolate was then transferred to rye agar (produced by steaming $200 \mathrm{~g}$ of rye seed in 1 liter of deionized water for $1 \mathrm{~h}$; to the resulting broth filtrate $15 \mathrm{~g}$ of Difco agar and 5 $\mathrm{g}$ of dextrose were added, after which the solution was adjusted to 1 liter using deionized water and autoclaved at $121^{\circ} \mathrm{C}$ for 20 min; 21), or V 8-agar (200 $\mathrm{ml}$ of V8 juice, 2 $\mathrm{g}$ of $\mathrm{CaCo}_{3}$, and $15 \mathrm{~g}$ of agar/1 liter of deionized water, autoclaved as above for 20 $\min ; 22)$. These transfers were used as pure cultures for further studies.

Pathogenicity tests. The floating leaflet bioassay as described by Davidse et al. (4) was utilized to test the pathogenicity of different isolates of $P$. infestans. Leaflets from 6- to 8-week-old potato plants (cvs. 
Superior and Nicola) were floated on sterile water in plastic Petri dishes $(10 \mathrm{~cm}$ in diameter) with the abaxial surface downward (three leaflets per dish). Each leaflet was inoculated using a $25-\mu$ l droplet of inoculum at a concentration of $10^{4}$ sporan$\mathrm{gia} / \mathrm{ml}$ obtained from V8 agar and chilled for $2 \mathrm{~h}$ at $6^{\circ} \mathrm{C}$ prior to inoculation. The inoculated floating leaflets were incubated at $15^{\circ} \mathrm{C}$ for 5 to 10 days. Sporulation on floating leaflets confirmed the pathogenicity of an isolate.

In addition, a greenhouse experiment was conducted using isolate MO-1 (collected in 1996 from a potato field in northern Morocco), which was compared for its aggressiveness to other genotypes culture collection at Cornell University). All references to $P$. infestans genotypes designated "US" are sensu Goodwin et al. (14). Two potato cultivars (Superior from the United States and Nicola from Europe) and three tomato cultivars from the United States (Bonny Best, Pixie, and Better Boy) were used in this experiment.

Healthy tomato (4 weeks old) and potato (8 weeks old) plants grown in the greenhouse were inoculated by spraying $150 \mathrm{ml}$ of inoculum solution per plant at a concentration of $10^{5}$ sporangia/ml, then placed in a dew chamber $(100 \%$ relative humidity $[\mathrm{RH}]$ at $20^{\circ} \mathrm{C}$ ) for 36 to $48 \mathrm{~h}$ before being returned to the greenhouse at $20^{\circ} \mathrm{C}$ and $80 \%$ RH until lesions appeared on potato and tomato leaves, stems, or both.

Sensitivity to metalaxyl. Radial growth of mycelia in metalaxyl-amended rye agar (US-1, US-6, and US-8, acquired from the

compared to their growth in metalaxyl-free rye agar was used to assess sensitivities of isolates to the fungicide. Metalaxyl (Ridomil 2E) at a concentration of 10 $\mu \mathrm{g} / \mathrm{ml}$ was added to melted rye agar after autoclaving. Agar plugs $(5 \mathrm{~mm})$ were cut from the edge of 2-week-old cultures and placed in the center of Petri dishes containing fresh media with and without metalaxyl $(5,20)$. There were five replicate dishes per isolate and each experiment was repeated once. Measurements were made at 5-day intervals for 15 days and the growth response for each isolate was calculated using the formula published by Deahl et al. (5).

Gpi and Pep alleles. The cellulose-acetate electrophoresis (CAE) technique was performed to identify the allozyme genotype of $P$. infestans isolates. CAE provides excellent resolution of allozyme genotypes at two loci: glucose 6 phosphate isomerase (Gpi) and peptidase (Pep). In this study, the $G p i$ and $P e p$ alleles were determined by CAE as developed by Goodwin et al. (15).

All material used was purchased from a commercial source. Tissue for electrophoresis consisted of a small quantity of mycelia and sporangia washed from infected tissue and then placed into $1.5-\mathrm{ml} \mathrm{mi}$ crocentrifuge tubes and centrifuged at $13,000 \times g$ for $1 \mathrm{~min}$ to pellet. Excess supernatant was poured off so that the remaining volume was $100 \mu \mathrm{l}$. The pellet was then ground by hand using a tapered pestle. Small aliquots of each sample were pipetted from the supernatant into wells on the sample well plate and the gel was

Table 1. Location and host (source) of Phytophthora infestans isolates collected during 1996 to 1998 in Morocco

\begin{tabular}{llllr}
\hline Year & Location & Region $^{\text {a }}$ & Host & No. of isolates \\
\hline 1996 & Larache & N & Potato & 15 \\
1997 & Larache & N & Potato & 8 \\
& Casablanca & C & Potato & 12 \\
& Fez & NE & Potato & 14 \\
& El Jadida & C & Tomato & 9 \\
& Fez & NE & Tomato & 14 \\
1998 & Casablanca & C & Potato & 14 \\
& Fez & NE & Potato & 16 \\
& Tarroudant & SE & Potato & 13 \\
& Fez & NE & Tomato & 16 \\
& Agadir & S & Tomato & 18 \\
\hline
\end{tabular}

${ }^{\mathrm{a}} \mathrm{N}=$ northern, $\mathrm{C}=$ central, $\mathrm{NE}=$ northeastern, $\mathrm{SE}=$ southeastern, and $\mathrm{S}=$ southern Morocco. Distance between regions was a minimum of 100 and a maximum of $800 \mathrm{~km}$.

Table 2. Pathogenicity of selected Phytophthora infestans isolates from Morocco and the United States on tomato and potato cultivars ${ }^{\mathrm{a}}$

\begin{tabular}{lcccccc}
\hline & \multicolumn{3}{c}{ Tomato cvs. } & & \multicolumn{2}{c}{ Potato cvs. } \\
\cline { 2 - 4 } \cline { 7 - 7 } Isolate $^{\mathbf{b}}$ & Bonny Best & Pixie & Better Boy & & Superior & Nicola \\
\hline MO-1 & ++ & + & ++ & & ++ & ++ \\
US-8 & + & + & + & & ++ & ++ \\
US-6 & ++ & ++ & ++ & & + & ++ \\
US-1 & - & - & - & & ++ & ++ \\
\hline
\end{tabular}

$\mathrm{a}(+)=$ less than $50 \%$ of leaves with lesions, $(++)=$ more than $50 \%$ of leaves with lesions, $(-)=$ no lesions 4 weeks after inoculation.

${ }^{\mathrm{b}} \mathrm{MO}-1$ = isolate from potato in Morocco; US-1, US-6, and US-8 were acquired from the culture collection at Cornell University. loaded. Blue dye was spotted along the origin to monitor the progress of electrophoresis and provide an orientation. Gels were stained after 15 to 20 min of electrophoresis using agar overlay or underlay. The allele bands were compared with known US-1, US-6, US-7, and US-8 genotypes acquired from the culture collection at Cornell University.

Mating types. Mating types were determined by pairing each Moroccan isolate with the known A1 (US-1) and A2 (US-8) cultures on Rye medium (6).

Criteria for genotype determination. Allozyme patterns of Gpi and Pep, metalaxyl sensitivity, and mating types were used as criteria for the genotype determination for Moroccan isolates, which were compared to known genotypes US-1, US-6, and US-8.

\section{RESULTS}

Collection of isolates. Between 1996 and1998, 149 pathogenic isolates of $P$. infestans were collected from commercial potato and tomato fields in different regions of Morocco. Most isolates were random samplings from a single lesion (from stem, leaf, fruit, or tuber). One isolate was collected from imported seed potato from Europe at the port of Casablanca (Table 1).

Pathogenicity tests. All 149 isolates were pathogenic when tested via the floating leaflet bioassay. In addition, the greenhouse experiment showed that the Moroccan isolate (MO-1) collected in 1996 from potato fields in northern Morocco was very aggressive when compared to other isolates from the United States (Table 2).

Mating type distribution. Mating type A1 was detected each year from both potato and tomato while A2 was obtained only from potato in 1998 . For potato, the ratio of A2 mating type isolates during these years increased from zero in 1996 to a ratio of $3: 1$ (A2:A1) of the total isolates collected in 1998; however, all 57 isolates from tomato were A1 in 1997 and 1998 (Table 3).

Metalaxyl sensitivity. All isolates collected from potato were either intermediate or insensitive to metalaxyl. All isolates from tomato in 1997 to 1998 (there was no late blight in 1996) were sensitive to metalaxyl (Table 3).

Genotype identification using allozyme analysis. All isolates collected from tomato fields in 1997 and 1998 had an allozyme pattern of allele Gpi 86/100 and allele Pep equal to $92 / 100$ (Table 4) and were sensitive to metalaxyl (Table 3 ).

All isolates collected from potato fields in 1996 and 1997 were the A1 mating type, pathogenic on tomato and potato, with an allozyme pattern of Gpi allele 100/100 and Pep 92/100 (Table 4), and were insensitive to metalaxyl (Table 3 ).

Isolates collected during 1998 from potato fields and imported potato seed were A2 mating type with an allozyme pattern 
of Gpi 100/100 and Pep 100/100 and were insensitive to phenylamide (metalaxyl). Other isolates, also collected in 1998 from potato fields, were A1 mating type with an allozyme pattern of Gpi 100/100 and Pep 100/100 (Fig. 1 and Table 4) and were insensitive to metalaxyl (similar to the genotype found in 1996 and 1997; Table 3).

\section{DISCUSSION}

There was a mating type shift within the $P$. infestans population in Morocco between 1996 and 1998. Analyses based on the mating type of different isolates collected from potato fields revealed for the first time the presence of the new genotype A2 (MO-3) in Morocco, and A1 (MO-4). The percentage of A1 present in Morocco decreased from $100 \%$ in 1997 to $26 \%$ in 1998. In potato fields in the Northeastern region (Fez), both mating types (A1 and A2) were identified in 1998, which indicates the potential for sexual reproduction of the pathogen in Morocco. Mating type A2 also was identified from imported potato seed from Europe, which suggests that the possible introduction of the A2 mating type of $P$. infestans occurred due to infected potato seed being imported from Europe. All $P$. infestans isolates collected from tomato were of the A1 mating type (1997 to 1998).

All isolates of $P$. infestans collected from potato fields were either metalaxylinsensitive or intermediate; however, all isolates collected from tomato were sensitive to metalaxyl. This suggests that the population structure of $P$. infestans changed during the last few years for isolates collected from potato but remained the same for isolates collected from tomato. This situation is similar to that in Brazil and Ecuador (8). A study published in 1998 by Oyarzun et al. (23) states that US-1 (A1 mating type) was exclusively found on tomato, results that are in contrast to recent studies conducted in North America where some genotypes are equally aggressive on both hosts (tomato and potato). Separate genotypes have been found in association with the two hosts in several parts of the world; therefore, this study concluded that the presence of aggressive genotypes in these regions is possible. Aggressive genotypes could be particularly destructive in developing countries where both tomato and potato are grown year-round in the same geographic region. Many such areas currently exist in Africa, Asia, and South America (23).

Migration probably played a role in increasing genetic diversity in the Moroccan population of $P$. infestans. The population in the past was composed of a single clonal lineage (the same as was found in 1997 to 1998 on tomato). The second migration of $P$. infestans may have occurred in recent years through imported potato seed from Europe. This new population is replacing an older population characterized by $G p i$
86/100 and Pep 92/100. This recent migrant population is very diverse and includes isolates with characteristics not previously seen in 1996 and 1997: A2 mating type, Gpi 100/100, Pep 92/100, and Pep 100/100 alleles.

In most cases, multiple isolates from the same field in Morocco were the same mating type; however, two isolates of the opposite mating type (A1 and A2) were collected in the same field in 1998. They were both insensitive to metalaxyl, but no evidence to date suggests that sexual reproduction has occurred, although it may in the future. If oospores are produced, $P$. infestans may overwinter in the soil without living host tissue and serve as another source of primary inoculum. Sexual reproduction also would generate greater genetic

Table 3. Mating type distribution and metalaxyl sensitivity of Phytophthora infestans in Morocco from 1996 to 1998

\begin{tabular}{llccc}
\hline Year & Host & No. of isolates analyzed & Mating type A1:A2 ratio & Metalaxyl sensitivity $^{\mathbf{a}}$ \\
\hline 1996 & Potato & 15 & $1: 0$ & Insensitive \\
1997 & Potato & 34 & $1: 0$ & Insensitive \\
& Tomato & 23 & $1: 0$ & Sensitive \\
1998 & Potato & 43 & $1: 3$ & Insensitive \\
& Tomato & 34 & $1: 0$ & Sensitive \\
\hline
\end{tabular}

a Metalaxyl-sensitive isolates have less than $10 \%$ mycelial growth of the control, intermediate isolates have between 10 and $60 \%$ mycelial growth of control, and metalaxyl-insensitive isolates have more than $60 \%$ mycelial growth of control at a metalaxyl concentration of $10 \mu \mathrm{g} / \mathrm{ml}$.

Table 4. Characterization of the four dominant genotypes of Phytophthora infestans in Morocco ${ }^{\mathrm{a}}$

\begin{tabular}{llcrrc}
\hline Moroccan genotype & Host & Mating type & Gpi & Pep & Year \\
\hline MO-1 & Potato $^{\text {b }}$ & A1 & $100 / 100$ & $92 / 100$ & $1996-1997$ \\
MO-2 & Tomato & A1 & $86 / 100$ & $92 / 100$ & $1997-1998$ \\
MO-3 & Potato & A2 & $100 / 100$ & $100 / 100$ & 1998 \\
MO-4 & Potato & A1 & $100 / 100$ & $100 / 100$ & 1998 \\
\hline
\end{tabular}

${ }^{\text {a }} \mathrm{Gpi}=$ glucose-6-phosphate isomerase and $P e p=$ peptidase alleles.

${ }^{\mathrm{b}}$ Late blight was not found on tomatoes in 1996.

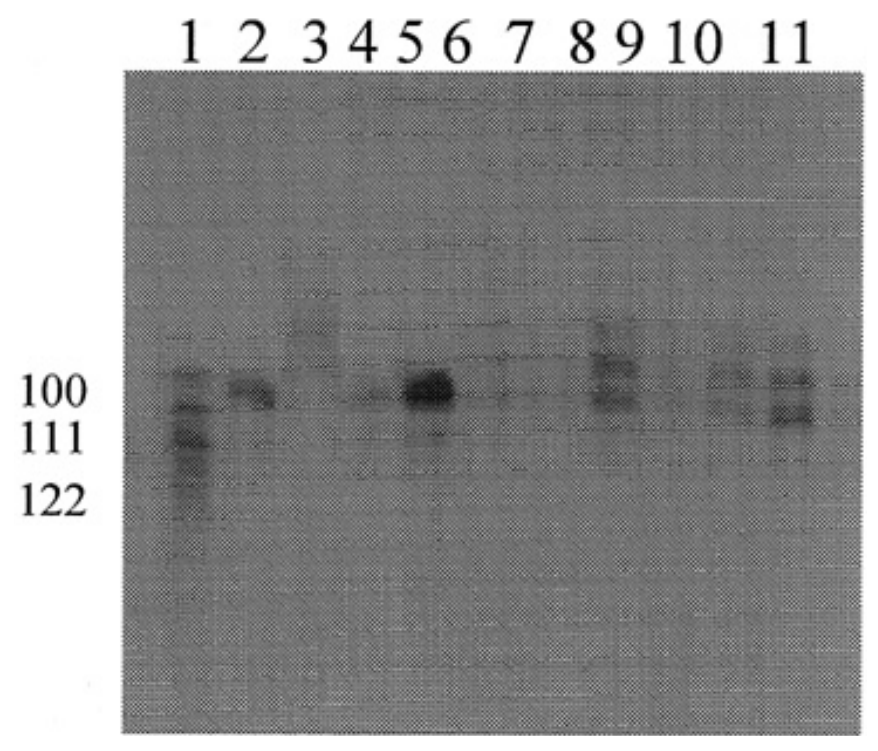

Fig. 1. Glucose-6-phosphate(Gpi) isomerase isozymes of Phytophthora infestans. Isolates 1 (genotype US-8) and 2 (genotype US-6) were used as references. Isolates 3 (A1 mating type), 4, and 5 (A2 mating type) were from potato; isolates $6,7,8,9,10$, and 11 (A1 mating type) were from tomato collected in Morocco. Location of 100, 111, and 122 homodimer bands are indicated on the left. 
and Rivera-Pena, A. 1995. Identification of mating types and metalaxyl resistance in north American populations of Phytophthora infestans. Am. Potato J. 72:35-49.

6. Deahl, K. L., Inglis, D. A., and De Muth, S. P. 1993. Test for resistance to metalaxyl in Phytophthora infestans isolates from Northwestern Washington. Am. Potato J. 70:779-795.

7. Drenth, A., Goodwin, S. B., Fry, W. E., and Davits, L. C. 1993 Genotypic diversity of Phytophthora infestans in the Netherlands revealed by DNA polymorphisms. Phytopathology 83:1087-1092.

8. Forbes, G. A., Escorbar, X. C., Ayala, C. C., Revelo, J., Ordones, M. E., Fry, B. A., Dopucet, K., and Fry, W. E. 1997. Population genetic structure of Phytophthora infestans in Ecuador. Phytopathology 87:375-380.

9. Forbes, G. A., Goodwin, S. B., Drenth, A., Oyarzum, P., Orddonez, M. E., and Fry, W. E. 1998. A global marker database for Phytophthora infestans. Plant Dis. 82:811-818.

10. Fry, W. E., Drenth, A., Spielman, L. J., Mantel, B. C., Davits, L. C., and Goodwin, S. B. 1991. Population genetic structure of Phytophthora infestans in the Netherlands. Phytopathology 81:1330-13361.

11. Fry, W. E., Goodwin, S. B., Dyer, A. T., Matuszak, J. M., Drenth, A., Tooley, P. W., Koh, Y. J., Cohen, B. A., Spielman, L. J., Deahl, K. L., Inglis, D. A., and Sandlan, K. P. 1993. Historical and recent migration of Phytophthora infestans: chronology pathways and implications. Plant Dis. 77:653661 .
12. Fry, W. E., Goodwin, S. B. Matuzsak, J. M., Spielman, L. J., Milgroom, M. G., and Drenth, A. 1992. Population genetics and international migration of Phytophthora infestans. Annu. Rev. Phytopathol. 30:107129.

13. Goodwin, S. B., Cohen, B. A., Deahl, K. L., and Fry, W. E. 1995. Migration from northern Mexico as the probable cause of recent genetic changes in population of Phytophthora infestans in the United States and Canada. Phytopathology 84:553-558.

14. Goodwin, S. B., Cohen, B. A., and Fry, W. E. 1994. Panglobal distribution of a single clonal lineage of Irish potato famine. Proc. Natl. Acad. Sci. USA 91:1591-1595.

15. Goodwin, S. B., Schneider, R. E., and Fry, W. E. 1995. Use of cellulose-acetate electrophoresis for rapid identification of allozyme genotypes of Phytophthora infestans. Plant Dis. 79:1181-1185.

16. Goodwin, S. B., Sujkowski, L. S., Dyer, A. T., Fry, B. A., and Fry, W. E. 1995. Direct detection of gene flow and probable sexual reproduction of Phytophthora infestans in northern North America. Phytopathology 85:473-479.

17. Goodwin, S. B., Sujkuwski, L. S., and Fry W. E. 1995. Rapid evolution of pathogenicity within clonal lineages of the potato late blight disease fungus. Phytopathology 85:669-676.

18. Gregory, P. H. 1983. Some major epidemics caused by Phytophthora. Page 271-278 in: Phytophthora: Its Biology, Taxonomy and Pathology. D. C. Erwin, S. Bartnicki-Garcia, and P. H. Tsao, eds. American Phytopa- thological Society, St. Paul, MN.

19. Hollomon, D. W. 1965. Isolation of Phy tophthora infestans from blighted leaves. Plant Pathol. 14:34-35.

20. Kadish, D., and Cohen, Y. 1988 Fitness of Phytophthora infestans isolates from metalaxyl-sensitive and resistant populations. Phytopathology 78:912-915.

21. Kannwischer, M. E., and Mitchell, D. J. 1978. The influence of a fungicide on the epidemiology of black shank of tobacco. Phytopathology 68:1760-1765.

22. Miller, P. M. 1955. V8 juice agar as general purpose medium for fungi and bacteria. Phytopathology 45:461-462.

23. Oyarzun, P. J., Pozo, A., Ordonez, M. E., Doucett, K., and Forbes, G. A. 1998. Host specificity of Phytophthora infestans on tomato and potato in Ecuador. Phytopathology 88:265-271.

24. Speilman, A. G., Drenth, A., Davidse, L. C., Sujkowski, L. J., Go, W., Tooley, P. W., and Fry, W. E. 1991. Second worldwide migration and population displacement of Phytophthora infestans. Plant Pathol. 40:422-430.

25. Sujkowski, L. S., Goodwin, S. B., Dyer, A. T., and Fry, W. E. 1994. Increased genotypic diversity via migration and possible occurrence of sexual reproduction of Phytophthora in festans in Poland. Phytopathology 84:201207.

26. Vartanian, V. G., and Endo, R. M. 1985. Overwintering hosts, compatibility types and races of Phytophthora infestans on tomato in southern California. Plant Dis. 69:516-519. 